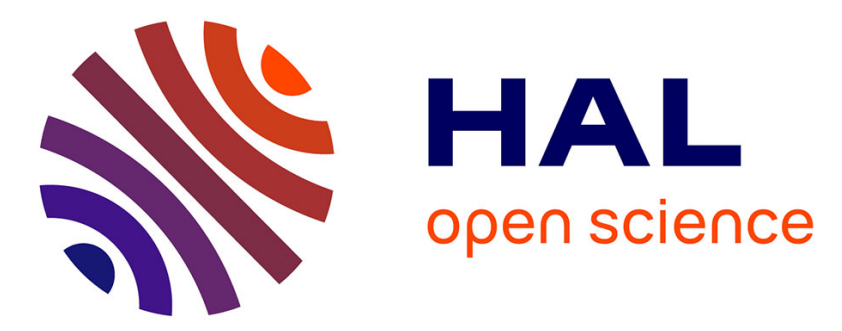

\title{
First-principles modeling of X-ray absorption spectra enlightens the processes of scandium sequestration by iron oxides
}

Mathieu Chassé, Marc Blanchard, Delphine Cabaret, Amélie Juhin, Delphine Vantelon, Georges Calas

\section{To cite this version:}

Mathieu Chassé, Marc Blanchard, Delphine Cabaret, Amélie Juhin, Delphine Vantelon, et al.. Firstprinciples modeling of X-ray absorption spectra enlightens the processes of scandium sequestration by iron oxides. American Mineralogist, 2020, 105 (7), pp.1099-1103. 10.2138/am-2020-7308 . hal02945509

\section{HAL Id: hal-02945509 https://hal.sorbonne-universite.fr/hal-02945509}

Submitted on 22 Sep 2020

HAL is a multi-disciplinary open access archive for the deposit and dissemination of scientific research documents, whether they are published or not. The documents may come from teaching and research institutions in France or abroad, or from public or private research centers.
L'archive ouverte pluridisciplinaire HAL, est destinée au dépôt et à la diffusion de documents scientifiques de niveau recherche, publiés ou non, émanant des établissements d'enseignement et de recherche français ou étrangers, des laboratoires publics ou privés. 


\section{First-Principles Modeling of X-Ray Absorption Spectra Enlightens the Processes of}

\section{Scandium Sequestration by Iron Oxides}

\section{REVISION 1}

4 Mathieu ChassÉ $^{1, *}$, Marc Blanchard ${ }^{2}$, Delphine CABARET $^{1}$, Amélie JUHIN $^{1}$, Delphine VANTELON ${ }^{3}$ \&

5 Georges CALAS ${ }^{1}$

6 'Sorbonne Université, Muséum National d'Histoire Naturelle, UMR CNRS 7590, IRD, Institut de

7 minéralogie, de physique des matériaux et de cosmochimie, IMPMC, 75005 Paris, France

$8{ }^{2}$ Géosciences Environnement Toulouse (GET), Observatoire Midi-Pyrénées, Université de Toulouse,

9 CNRS, IRD, UPS, 14 avenue Edouard Belin, 31400 Toulouse, France

$10{ }^{3}$ SOLEIL synchrotron, L'Orme des Merisiers, Saint-Aubin, BP 48, 91192 Gif-sur-Yvette, France

$11{ }^{*}$ Corresponding author: mathieu.chasse@,normalesup.org

\section{Abstract}

14 Scandium is often associated with iron oxides in the environment. Despite the use of scandium as a

15 geochemical tracer and the existence of world-class supergene deposits, uncertainties on speciation

16 obscure the processes governing its sequestration and concentration. Here, we use first-principles

17 approaches to interpret experimental $K$-edge $X$-ray absorption near-edge structure spectra of scandium

18 either incorporated in or adsorbed on goethite and hematite, at concentrations relevant for the

19 environment. This modeling helps to interpret the characteristic spectral features, providing key

20 information to determine scandium speciation when associated with iron oxides. We show that

21 scandium is substituted into iron oxides at low concentration without modifying the crystal structure. 
This is a preprint, the final version is subject to change, of the American Mineralogist (MSA)

Cite as Authors (Year) Title. American Mineralogist, in press.

DOI: https://doi.org/10.2138/am-2020-7308

22 When scandium is adsorbed onto iron oxide surfaces, the process occurs through outer-sphere

23 complexation with a reduction in the coordination number of the hydration shell. Considering available

24 X-ray absorption spectra from laterites, the present results confirm that scandium adsorption onto iron

25 oxides is the dominant mechanism of sequestration in these geochemical conditions. This speciation

26 explains efficient scandium recovery through mild metallurgical treatments of supergene lateritic ores.

27 The specificities of scandium sorption mechanisms are related to the preservation of adsorbed

28 scandium in million-years old laterites. These results demonstrate the emerging ability to precisely

29 model fine X-ray absorption spectral features of trace metals associated with mineral phases relevant to

30 the environment. It opens new perspectives to accurately determine trace metals speciation from high-

31 resolution spatially-resolved X-ray absorption near-edge structure spectroscopy in order to constrain

32 the molecular mechanisms controlling their dynamics.

33 Keywords: Scandium, XANES, Ab-Initio Calculations, Speciation, Fe oxides, Sorption, Critical Zone.

\section{Introduction}

In the critical zone (CZ: the interface between geological, hydrological and atmospheric compartments where rocks interact with air, water and biota), iron oxides, in particular goethite $(\alpha-\mathrm{FeO}(\mathrm{OH}))$ and hematite $\left(\alpha-\mathrm{Fe}_{2} \mathrm{O}_{3}\right)$, are ubiquitous. They affect the biogeochemical cycling of many elements as they bind through adsorption onto mineral surfaces or incorporate within the crystal structure (Brown and Calas, 2012). Adsorption can also be followed by diffusive penetration into the interior of mineral

41 particles through lattice or pore diffusion (Brümmer et al. 2013). Recurring changes of the

42 biogeochemical conditions within the $\mathrm{CZ}$ lead to dynamic dissolution and crystallization of Fe oxides

43 controlling the fate of trace metals (e.g., Frierdich et al., 2011).

44 The fate of scandium $(\mathrm{Sc})$ in the $\mathrm{CZ}$ is a case in point. Scandium is used as a conservative element to 45 model mass transfer during weathering (e.g., Eshel et al., 2015). The absence of accessory Sc minerals 
This is a preprint, the final version is subject to change, of the American Mineralogist (MSA)

Cite as Authors (Year) Title. American Mineralogist, in press.

DOI: https://doi.org/10.2138/am-2020-7308

in supergene contexts (Samson and Chassé 2016) implies that its sequestration in the CZ depends on

47

the rock-forming phases present. Scandium association with Fe oxides is well-known (Norman and Haskin 1968) and illustrated by worldwide findings of Sc-rich laterites (e.g., Aiglsperger et al., 2016; Chassé et al., 2017; Teitler et al., 2019), expected to become a potential source for this critical metal. Nonetheless, the processes of Sc trapping in laterites remain elusive. Isomorphous substitution in $\mathrm{Fe}$ oxides or sequestration by adsorption have been invoked in Sc-bearing laterites (Chassé et al. 2017; Vind et al., 2018; Ulrich et al., 2019), making necessary an accurate determination of Sc speciation to constrain Sc dynamics in the CZ.

In this perspective, the chemical selectivity and high sensitivity of X-ray absorption spectroscopy proved to be invaluable (Chassé et al. 2017, 2019). The low Sc concentration in natural systems requires the use of Sc $K$-edge X-ray absorption near-edge structure (XANES) spectroscopy. Nonetheless, a precise analysis of Sc speciation based on XANES spectroscopy requires theoretical modeling to understand the origin of the spectral features. This has been made for the first time on the Sc $K$-edge XANES spectra of mineral compounds using first-principles calculations (Chassé et al., 2018). We apply this density functional theory (DFT) approach to model XANES spectra of Sc trapped by Fe oxides, stressing the interest of the method to unravel the role of incorporation and sorption processes on Sc fate in the $\mathrm{CZ}$.

\section{Experimental methods and theoretical approach}

We studied a Sc-chloride solution (ca. $1 \mathrm{wt} \%$ ), Sc-substituted (ca. $1 \mathrm{wt} \%$ ) and Sc-adsorbed (ca. $0.1 \mathrm{wt}$ \%) goethite and hematite, and Sc-adsorbed montmorillonite $\left((\mathrm{Na}, \mathrm{Ca})_{0.3}(\mathrm{Al}, \mathrm{Mg})_{2} \mathrm{Si}_{4} \mathrm{O}_{10}(\mathrm{OH})_{2} \cdot \mathrm{nH}_{2} \mathrm{O}\right.$, ca. $1 \mathrm{wt} \%$ ). The Sc-chloride solution was prepared by dilution of $\mathrm{Sc}^{3+}$ chloride hexahydrate powder.

Scandium-substituted goethite was prepared by maintaining a ferrihydrite suspension at $65^{\circ} \mathrm{C}$ for two days after precipitation from $\mathrm{Fe}^{3+}$ nitrate at a basic $\mathrm{pH}$ in presence of $\mathrm{Sc}$ chloride. Scandium-substituted 
This is a preprint, the final version is subject to change, of the American Mineralogist (MSA)

Cite as Authors (Year) Title. American Mineralogist, in press.

DOI: https://doi.org/10.2138/am-2020-7308

hematite was obtained by dehydroxylation of goethite through heating. Scandium-adsorbed samples

71

72

73

74

75

76

77

78

79

80

81

82

83

84

85

86

87

88

89

90

91

92 93

were prepared by adding a Sc-chloride solution to Sc-free synthetic goethite, hematite or natural

montmorillonite, later separated and dried. Details are given in Supplemental Material.

We recorded Sc $K$-edge XANES spectra at the LUCIA beamline (SOLEIL synchrotron) using an

$\mathrm{Si}(311)$ double crystal monochromator calibrated against a $\mathrm{Sc}_{2} \mathrm{O}_{3}$ standard. Measurements were

performed in the energy range (4400-4800) eV with energy steps of $(5,0.2,0.5$ and 1$) \mathrm{eV}$ in energy

ranges of (4400-4485) eV, (4485-4534) eV, (4534-4586) eV and (4586-4800) eV, respectively.

Spectra were collected at room temperature, under vacuum in XRF mode on pellets obtained from

powdered material and mounted on a holder between two $2 \mu \mathrm{m}$ thick Ultralene ${ }^{\circledR}$ films, using a four-

element silicon drift detector (SDD). Two spectra were recorded for each reference with a counting

time of ca. $50 \mathrm{~s}$ per spectrum. The spectra acquired for each reference were merged before background

subtraction and normalization. Details can be found in Chassé et al. (2017).

Theoretical XANES spectra were calculated using the Quantum ESPRESSO plane-wave based DFT suite of codes (Giannozzi et al. 2009) in the generalized gradient approximation (Perdew-Burke-

Ernzerhof parametrization, Perdew et al., 1996). The charge density is obtained via a relaxation of the atomic positions and a self-consistent field calculation using the PWscf code. Then, XANES spectra are computed in a continued fraction approach using the XSpectra code (Taillefumier et al. 2002;

Gougoussis et al. 2009). Computational details are given in Supplemental Material.

Charge density calculations were initialized using cell parameters and atomic positions obtained from structure relaxations of goethite (Ducher et al. 2015) and hematite (Blanchard et al. 2008). Either one or two adjacent Sc atoms (isolated or paired models, Supplemental Material) were substituted for Fe atoms into the crystal structure to model Sc-substituted goethite (Fig. 1a) and hematite (Fig. 1b). It corresponds to ca. $2 \mathrm{wt} \%$ and $4 \mathrm{wt} \%$ Sc for goethite models and ca. $1 \mathrm{wt} \%$ and $2 \mathrm{wt} \%$ Sc for hematite models. Physiosorbed Sc was modeled by a 6-fold coordinated water complex (Rudolph and Pye 
94 2000).

95

\section{Results and discussion}

96 Spectral signature of scandium associated with iron oxides

97 Experimental Sc $K$-edge XANES spectra of Sc-substituted goethite and hematite exhibit four major

98 features in the main edge $\left(\mathrm{A}_{0}, \mathrm{~A}, \mathrm{~B}\right.$ and $\mathrm{C}$, Fig. 2a,b), respectively located at ca. $4501 \mathrm{eV}, 4508 \mathrm{eV}$,

$994512 \mathrm{eV}$ and $4524 \mathrm{eV}$. In the pre-edge region, two low-intensity features $\left(\mathrm{P}_{1}\right.$ and $\left.\mathrm{P}_{2}\right)$, observed in

100 compounds with six-fold coordinated Sc (Lindqvist-Reis et al. 2006; Oberti et al. 2006; Chassé et al.

101 2018), are present at ca. $4492 \mathrm{eV}$ and $4494 \mathrm{eV}$. The position, shape and intensity of the main-edge

102 features are reproduced in the theoretical spectra obtained from structural models of Sc-incorporated

103 goethite and hematite indicating the robustness of the calculation method and the validity of the

104 structural models (Fig. 2a,b). In the pre-edge region, the $\mathrm{P}_{2}$ feature is less intense and split in two

105 components in the theoretical spectra (close view, Figs. 3 and S1). When Sc atoms are paired in the

106 model structure of goethite, a feature appears at higher energy (Fig. 3, *).

107 To interpret the pre-edge spectra, the DOS, correlated to the spectral features, are projected on the

108 absorbing Sc (Sc*) and its first neighbors (Fig. 3 and S1). These DOS describe, for each energy level,

109 the number of empty states available that can be reached with a certain transition probability by the

110 photoelectron during XANES experiments. The contribution of electric quadrupole (E2) transitions to

111 the $\mathrm{P}_{1}$ and $\mathrm{P}_{2}$ features, corresponding respectively to $1 s \rightarrow 3 d-t_{2 \mathrm{~g}}$ and $1 s \rightarrow 3 d-e_{\mathrm{g}}$ transitions is minor

112 (Figs. 3 and S1). Electric dipole (E1) transitions $1 s \rightarrow 4 p$ dominate the $\mathrm{P}$ features. They reflect local

113 transitions due to $4 p-3 d$ hybridization of $\mathrm{Sc}^{*}$, observed for non-centrosymmetric sites, such as

114 tetrahedra (Knoll et al. 2014) or distorted octahedra (Chassé et al. 2018). Non-local transitions also

115 contribute to E1 transitions and result from orbital mixing between the $4 p$ orbitals of Sc* and $3 d$

116 orbitals of its nearest Fe neighbors via the empty $2 p$ orbitals of the oxygen ligands. This orbital mixing

117 of Sc* is documented for Sc-bearing compounds exhibiting $3 d$ neighbors (Chassé et al. 2018). The 
This is a preprint, the final version is subject to change, of the American Mineralogist (MSA)

Cite as Authors (Year) Title. American Mineralogist, in press.

DOI: https://doi.org/10.2138/am-2020-7308

118 DOS show that the energy difference between $3 d-t_{2 \mathrm{~g}}$ and $3 d-e_{\mathrm{g}}$ orbitals, i.e. the crystal field splitting

119 energy (10Dq), is greater for Sc than for Fe, inducing the splitting of the $\mathrm{P}_{2}$ feature. The $10 \mathrm{Dq}$ value for

120 Fe tends to be underestimated compared to experiments (Ducher et al. 2016). A higher 10Dq would

121 lead to the superimposition of the theoretical $\mathrm{P}_{2}$ features, matching experimental spectra. When $\mathrm{Sc}$

122 atoms are paired in the model structure of goethite and hematite, non-local E1 transitions may also

123 arise from orbital mixing with $3 d$ orbitals of the adjacent Sc ions. Due to the absence of core hole on

124 these neighbors, the position of the $3 d$ orbitals is at higher energies, leading to additional features on

125 the calculated pre-edge (Figs. 3 and S1, shown as *, at ca. $4497 \mathrm{eV}$ for goethite and at ca. $4496 \mathrm{eV}$ and

$1264498 \mathrm{eV}$ for hematite), absent from experimental spectra. This additional feature is unambiguous in the

127 hematite spectrum when plotting the different polarization dependent components of the isotropic

128 spectrum (Fig. S2). Such additional pre-edge features are also observed for Sc oxides (Chassé et al.

129 2018) and for other $3 d$ ions in oxides such as $\mathrm{Ti}^{4+}$ (Cabaret et al. 2010) and $\mathrm{Cr}^{3+}$ ions (Verger et al.

130 2016) accounting for the presence of neighbors with the same nature as the absorbing atom.

131

132 Atomic environment of scandium associated to iron oxides

133 The agreement between experimental and theoretical spectra in the main edge confirms the structural

134 incorporation of Sc in the synthesized Fe oxides. Despite small discrepancies in the energy and

135 intensity of some transitions, inherent to the limitation of DFT-based methods to model the core-hole

136 electron interaction and the $3 d$ electron-electron repulsion (Cabaret et al. 2010), the transitions

137 observed in the pre-edge are reproduced and interpreted from the projected DOS. The absence of the

138 feature diagnostic of Sc pairing (Figs. 3 and S1, *) in experimental spectra of goethite and hematite

139 indicates that substituted Sc sites are isolated. A correct modeling of the spectra does not require

140 volume-cell relaxation. At low Sc concentrations, below a few wt $\%$, the structure of these Fe oxides

141 accommodates Sc substitution without significant changes in the cell volume, the changes in Sc-O 
This is a preprint, the final version is subject to change, of the American Mineralogist (MSA)

Cite as Authors (Year) Title. American Mineralogist, in press.

DOI: https://doi.org/10.2138/am-2020-7308

142 distances relative to Fe-O distances remaining low $(<7 \%$, Supplemental Table S1). When Sc is

143 structurally incorporated, it is dispersed at low concentration, without modifying the Fe-oxides cell

144 volume.

145 Scandium $K$-edge XANES spectra of Sc-adsorbed goethite and hematite are similar and alike that of Sc

146 adsorbed on Fe-free clay surfaces (Fig. 2c). Specific affinity for a given site of Fe-oxide surfaces and

147 adsorption through covalent bonding is thus excluded. Scandium binding must occur through outer

148 sphere complexes. Comparison with such Sc complexes indicates that the splitting of the pre-edge

149 associated with the low intensity of the main edge is consistent with six-fold coordinated complexes

150 but incompatible with higher coordination numbers (Fig. 2c, Sc-chloride solution and Lindqvist-Reis et

151 al., 2006; Yamaguchi et al., 1997). A theoretical spectrum is calculated using an isolated 6-fold

152 coordinated $\left[\mathrm{Sc}\left(\mathrm{H}_{2} \mathrm{O}\right)_{4}(\mathrm{OH})_{2}\right]^{+}$complex, $\mathrm{Sc}(\mathrm{OH})_{2}{ }^{+}$being the dominant species at the slightly acidic $\mathrm{pH}$

153 of adsorption experiments (Wood and Samson 2006). The calculated spectrum reproduces the major

154 features exhibited by experimental spectra (A and B, Fig. 2c). The splitting of the pre-edge and the

155 relative intensity of the two features is reproduced $\left(\mathrm{P}_{1}\right.$ and $\mathrm{P}_{2}$, Fig. 2c). Despite discrepancies in this

156 region arising from the simpleness of the model, the closeness between the calculated spectrum and the

157 experimental spectra of adsorbed Sc indicates that adsorption results in a reduction of the coordination

158 number of the $\mathrm{Sc}^{3+}$ complex. This complex is seven- to nine-fold coordinated in solution

159 (Vchirawongkwin et al. 2012, illustrated by the spectrum of the Sc-chloride solution, Fig. 2c) and six-

160 fold coordinated at the surface of Fe oxides (illustrated by the spectrum of Sc-adsorbed goethite and

161 hematite, Fig. 2c). The lability of the $\mathrm{Sc}^{3+}$ hydration shell supports this observation (Migliorati and

162 D’Angelo 2016).

164 Mechanisms of scandium sequestration by iron oxides in the critical zone

165 First-principles calculations do not show significant difference of affinity for Sc substitution in goethite 
This is a preprint, the final version is subject to change, of the American Mineralogist (MSA)

Cite as Authors (Year) Title. American Mineralogist, in press.

DOI: https://doi.org/10.2138/am-2020-7308

166 or hematite $\left(\Delta \mathrm{E}_{\mathrm{Gt}-\mathrm{Hem}}=0.33 \mathrm{eV}\right.$, Supplemental Material and Table S2). Preferential incorporation into

167 goethite (Ulrich et al. 2019) or hematite (Vind et al., 2018) must reflect the role of the conditions of

168 formation in determining the nature of the phase incorporating Sc, as shown for lutetium (Yokosawa et

169 al. 2019). In particular, differences in specific surface area or distinct precursor phases during Fe oxides

170 crystallization can explain variations in affinity for Sc. Sorption to goethite in lateritic Fe oxide-rich

171 horizons plays a major role in Sc trapping and concentration processes (Chassé et al. 2019). The

172 theoretical modeling of the spectra of outer-sphere Sc complexes exhibit features for which the

173 position, intensity and shape are comparable to experimental spectra of Sc-adsorbed species and bulk

174 lateritic samples (Fig. 2c). The agreement with experimental spectra of Sc-substituted goethite and

175 hematite excludes trapping by structural incorporation within crystallized Fe oxides in supergene

176 contexts, despite the existence of a solid solution $\mathrm{Fe}_{\mathrm{x}} \mathrm{Sc}_{(1-\mathrm{x})} \mathrm{O}(\mathrm{OH})$ in mild hydrothermal conditions $(70$

$177{ }^{\circ} \mathrm{C}$, Levard et al., 2018). Subtle differences between spectra of lateritic samples and Sc-adsorbed Fe

178 oxides (Fig. 2c, +), close to major features observed in Sc-substituted reference spectra, indicate minor

179 incorporation. With aging, as other metallic ions (Brümmer et al., 2013), Sc could penetrate Fe oxides

180 following adsorption processes enhanced by nanoporosity or lattice diffusion. The physico-chemical

181 parameters and growth kinetics are key determinants of the mechanism of Sc sorption. At increasing

182 metal concentration in solution, the process of adsorption through complexation at goethite surface may

183 be replaced by the formation of surface precipitates and structural incorporation, such as is the case for

184 nickel (Ugwu et al. 2019). At environmental conditions, with low Sc concentrations $(<$ a few tenth

185 of $\mathrm{wt} \%$ ) and room temperature (ca. $30^{\circ} \mathrm{C}$ on average under tropical climates), the surface complexation

186 process and slow kinetics must favor Sc adsorption onto goethite at the expense of structural

187 incorporation. In particular, the kinetics of this process in competition with successive dissolution and

188 crystallization processes may lead to the preservation of $\mathrm{Sc}$ complexes during the formation and

189 evolution of lateritic profiles. 


\section{Implications}

192 A speciation explaining mineral processing results. The speciation of critical metals has direct

193 implications for ore processing. For instance, cobalt sorption to goethite is mainly irreversible when

194 forming monodentate complexes while leaching remains efficient when polydentate polynuclear

195 complexes form (Ugwu and Sherman, 2017). The preservation of Sc sorbed onto Fe oxides surfaces in

196 laterites explains why Sc is efficiently recovered from lateritic ores using ion exchange (79\% recovery,

197 Williams-Jones and Vasyukova, 2018) or high-pressure acid leaching processes (94 \% recovery with

198 limited Fe-oxides dissolution, Wang et al., 2011).

199 An original sorption process controlling Sc fate in the critical zone. The nature of the adsorption

200 process may be of importance to the stability of Sc sorption after aging. The exchange of water

201 molecules inside the solvation shell of Sc with the solvent is eased by the existence of a far-coordinated

202 water molecule capping the complex (Migliorati and D'Angelo 2016), facilitating geometric changes

203 required for Sc adsorption and stabilizing the six-fold coordinated complex. The persistence of

204 adsorbed Sc species in million-years old laterites may result from this original sorption mechanism.

205 A promising tool to study the speciation of trace metals in the critical zone. This study

206 demonstrates that state-of-the-art first-principles calculations can reproduce XANES spectra of metals

207 associated with phases ubiquitous in the CZ. The complexity of the pathways leading to Sc trapping in

208 the $\mathrm{CZ}$ and their dependence to varying environmental conditions are evidenced. As for other trace

209 metals, experimental sequestration on model systems prepared in diverse but controlled conditions are

210 required as references to determine speciation in natural contexts. This theoretical tool, combined to

211 XANES, offers a new opportunity to make the link between experiments and natural environments to

212 obtain direct information on the molecular environment of trapping at trace concentration.

213 Future directions for first-principles-assisted investigation in environmental mineralogy. X-ray 
This is a preprint, the final version is subject to change, of the American Mineralogist (MSA)

Cite as Authors (Year) Title. American Mineralogist, in press.

DOI: https://doi.org/10.2138/am-2020-7308

214 absorption spectroscopy has become a central tool in environmental sciences (Brown and Calas 2012).

215 In the case of transition elements, the pre-edge features are used to determine element speciation but

216 their understanding is still complicated by the limitation of DFT-based approaches in this region. A

217 better modeling of the core-hole effects and of electron-electron interactions in DFT-based software is

218 developed (e.g., Cabaret et al. 2010) and will further improve the agreement between experimental and

219 calculated pre-edge spectra. Another direction, specific to adsorbed elements, would be to combine

220 DFT-based calculations of X-ray absorption spectra with DFT-based molecular dynamic simulations to

221 determine the molecular environments of adsorption and their energies (e.g., Watts et al. 2019).

\section{Acknowledgements}

224 We thank Benoît Baptiste, Ludovic Delbes and the late Jean-Louis Robert for experimental support. We

225 acknowledge SOLEIL for provision of synchrotron radiation facilities and thank the staff of the LUCIA

226 beamline (Proposal No. 20150692). Computer facilities were provided by GENCI-IDRIS (Projects

227 Nos. A0020906863 and A0040906863). This work was funded by the Institut universitaire de France.

\section{References}

230 Aiglsperger, T., Proenza, J.A., Lewis, J.F., Labrador, M., Svojtka, M., Rojas-Purón, A., Longo, F. and 231 Durišová, J. (2016) Critical metals (REE, Sc, PGE) in Ni laterites from Cuba and the Dominican

232 Republic. Ore Geology Reviews, 73, 127-147.

233 Blanchard, M., Lazzeri, M., Mauri, F. and Balan, É. (2008) First-Principles Calculation of the Infrared

234 Spectrum of Hematite. American Mineralogist, 93, 1019-1027.

235 Brown Jr. G.E. and Calas G. (2012) Mineral-Aqueous Solution Interfaces and Their Impact on the

236 Environment. Geochemical Perspectives, 1, 483-742.

237 Brümmer, G.W., Barrow, N.J. and Fischer, L. (2013) Effect of Porosity of Goethite on the Sorption of

238 Six Heavy Metal Ions: Sorption of Metals by Different Goethites. European Journal of Soil Science, 
Cabaret, D., Bordage, A., Juhin, A., Arfaoui, M., and Gaudry, E. (2010) First-Principles Calculations of X-Ray Absorption Spectra at the $K$-Edge of $3 d$ Transition Metals: an Electronic Structure Analysis of the Pre-Edge. Physical Chemistry Chemical Physics, 12, 5619-5633.

243 Chassé, M., Griffin, W.L., O’Reilly, S.Y. and Calas, G. (2017) Scandium Speciation in a World-Class

244 Lateritic Deposit. Geochemical Perspectives Letters, 3, 105-114.

245 Chassé, M., Juhin, A., Cabaret, D., Delhommaye, S., Vantelon, D. and Calas, G. (2018) Influence of

246 Crystallographic Environment on Scandium $K$-Edge X-Ray Absorption Near-Edge Structure Spectra.

247 Physical Chemistry Chemical Physics, 20, 23903.

248 Chassé, M., Griffin, W.L., O’Reilly, S.Y. and Calas, G. (2019) Australian Laterites Reveal Mechanisms Governing Scandium Dynamics in the Critical Zone. Geochimica Cosmochimica Acta, 260, 292-310.

250 Ducher, M., Blanchard, M., Vantelon, D., Nemausat, R. and Cabaret, D. (2016) Probing the Local 251 Environment of Substitutional $\mathrm{Al}^{3+}$ in Goethite Using X-Ray Absorption Spectroscopy and First252 Principles Calculations. Physics and Chemistry of Minerals, 43, 1-11.

253 Eshel, G., Lin, C. and Banin, A. (2015) Novel Approach for Quantitatively Estimating Element 254 Retention and Material Balances in Soil Profiles of Recharge Basins Used for Wastewater Reclamation. 255 Science of the Total Environment, 502, 517-525.

256 Frierdich, A.J., Luo, Y. and Catalano, J.G. (2011) Trace Element Cycling Through Iron Oxide Minerals 257 During Redox-Driven Dynamic Recrystallization. Geology, 39, 1083-1086.

258 Giannozzi, P., Baroni, S., Bonini, N., Calandra, M., Car, R., Cavazzoni, C., Ceresoli, D., Chiarotti, 259 G.L., Cococcioni, M., Dabo, I., Dal Corso, A., De Gironcoli, S., Fabris, S., Fratesi, G., Gebauer, R., 260 Gerstmann, U., Gougoussis, C., Kokalj, A., Lazzeri, M., Martin-Samos, L., Marzari, N., Mauri, F., 261 Mazzarello, R., Paolini, S., Pasquarello, A., Paulatto, L., Sbraccia, C., Scandolo, S., Sclauzero, G., 262 Seitsonen, A.P., Smogunov, A., Umari, P. and Wentzcovitch, R.M. (2009) QUANTUM ESPRESSO: A 263 Modular and Open-Source Software Project for Quantum Simulations of Materials. Journal of Physics: 264 Condensed Matter, 21, 395502.

265 Gougoussis, C., Calandra, M., Seitsonen, A.P. and Mauri, F. (2009) First-Principles Calculations of X266 Ray Absorption in a Scheme Based on Ultrasoft Pseudopotentials: From $\alpha$-Quartz to High- $T_{c}$ 267 Compounds. Physical Review B, 80, 1-8.

268 Knoll, S.M., Rovezzi, M., Zhang, S., Joyce, T.B., and Moram, M.A. (2014) Electronic Structure and 269 Local Distortions in Epitaxial ScGaN Films. Journal of Physics: Condensed Matter, 26, 225801.

270 Levard, C., Borschneck, D., Grauby, O., Rose, J. and Ambrosi, J.-P. (2018) Goethite, a Tailor-Made 271 Host for the Critical Metal Scandium: The $\mathrm{Fe}_{x} \mathrm{Sc}_{(1-x)} \mathrm{OOH}$ solid solution. Geochemical Perspectives 
Letters, 9, 16-20.

273 Lindqvist-Reis, P., Persson, I. and Sandström, M. (2006) The Hydration of the Scandium(III) Ion in

274 Aqueous Solution and Crystalline Hydrates Studied by XAFS Spectroscopy, Large-Angle X-Ray

275 Scattering and Crystallography. Dalton Transactions, 32, 3868-3878.

276

277

278

279

280

281

282

283

284

285

286

287

288

289

290

291

292

293

294

295

296

297

298

299

300

301

302

303

304

Migliorati, V. and D’Angelo, P. (2016) Unraveling the Sc ${ }^{3+}$ Hydration Geometry: The Strange Case of the Far-Coordinated Water Molecule. Inorganic Chemistry, 55, 6703-6711.

Norman, J.C. and Haskin, L.A. (1968) The Geochemistry of Sc: A Comparison to the Rare Earths and Fe. Geochimica Cosmochimica Acta, 32, 93-108.

Oberti, R., Quartieri, S., Dalconi, M.C., Boscherini, F., Iezzi, G., Boiocchi, M., and Eeckhout, S.G. (2006) Site Preference and Local Geometry of Sc in Garnets: Part I. Multifarious Mechanisms in the Pyrope--Grossular Join. American Mineralogist, 91, 1230-1239.

Perdew, J. P., Burke, K. and Ernzerhof, M. (1996) Generalized Gradient Approximation Made Simple. Physical Review Letters, 77, 3865-3868.

Rudolph, W.W. and Pye, C.C. (2000) Raman Spectroscopic Measurements of Scandium(III) Hydration in Aqueous Perchlorate Solution and Ab Initio Molecular Orbital Studies of Scandium(III) Water Clusters: Does Sc(III) Occur as a Hexaaqua Complex? The Journal of Physical Chemistry A, 104, 1627-1639.

Samson, I.M. and Chassé, M. (2016) Scandium. In W.M. White, Ed., Encyclopedia of Geochemistry, p. 1-5. Springer International Publishing, Cham.

Taillefumier, M., Cabaret, D., Flank, A.-M. and Mauri, F. (2002) X-ray Absorption Near-Edge Structure Calculations with the Pseudopotentials: Application to the $K$-edge in Diamond and $\alpha$-Quartz. Physical Review B, 66, 195107.

Teitler, Y., Cathelineau, M., Ulrich, M., Ambrosi, J.-P., Muñoz, M. and Sevin, B. (2019) Petrology and Geochemistry of Scandium in New Caledonian Ni-Co Laterites. Journal of Geochemical Exploration, 196, 131-155.

Ugwu, I.M. and Sherman, D.M. (2017) Irreversibility of Sorption of Cobalt to Goethite $(\alpha-\mathrm{FeOOH})$ and Disparities in Dissolution of Aged Synthetic Co-Goethite. Chemical Geology, 467, 168-176.

Ugwu, I.M., Sherman, D.M. and Bacon, C.G.D. (2019) Sorption of Nickel Onto Goethite ( $\alpha-\mathrm{FeOOH})$ and Desorption Kinetics of Aged Synthetic Ni-Goethite: Implication for Ni Laterite Ore. Chemical Geology, 509, 223-233.

Ulrich, M., Cathelineau, M., Muñoz, M., Boiron, M.-C., Teitler, Y. and Karpoff, A.-M. (2019) The Relative Distribution of Critical (Sc, REE) and Transition Metals (Ni, Co, Cr, Mn, V) in Some NiLaterite Deposits of New Caledonia. Journal of Geochemical Exploration, 197, 93-113. 
305 Vchirawongkwin, V., Kritayakornupong, C., Tongraar, A. and Rode, B.M. (2012) Characterization of

306 Structure and Dynamics of an Aqueous Scandium(III) Ion by an Extended Ab Initio QM/MM

307 Molecular Dynamics Simulation. Dalton Transactions, 41, 11889.

308 Verger, L., Dargaud, O., Rousse, G., Rozsályi, E., Juhin, A., Cabaret, D., Cotte, M., Glatzel, P., and

309 Cormier, L. (2016) Spectroscopic properties of $\mathrm{Cr}^{3+}$ in the spinel solid solution $\mathrm{ZnAl}_{2-\mathrm{x}} \mathrm{Cr}_{\mathrm{x}} \mathrm{O}_{4}$. $\mathrm{Physics}$ 310 and Chemistry of Minerals, 43, 33-42.

311 Vind, J., Malfliet, A., Bonomi, C., Paiste, P., Sajó, I.E., Blanpain, B., Tkaczyk, A.H., Vassiliadou, V. 312 and Panias, D. (2018) Modes of Occurrences of Scandium in Greek Bauxite and Bauxite Residue.

313 Mineral Engineering, 123, 35-48.

314 Wang, W., Pranolo, Y. and Cheng, C.Y. (2011) Metallurgical Processes for Scandium Recovery from 315 Various Resources: a Review. Hydrometallurgy, 108, 100-108.

316 Watts, H.D., O’Day, P.A., and Kubicki, J.D. (2019) Gibbsite (100) and Kaolinite (100) Sorption of

317 Cadmium(II): A Density Functional Theory and XANES Study of Structures and Energies. The Journal

318 of Physical Chemistry A, 123, 6319-6333.

319 Williams-Jones, A.E. and Vasyukova, O.V. (2018) The Economic Geology of Scandium, the Runt of 320 the Rare Earth Element Litter. Economic Geology, 113, 973-988.

321 Wood, S.A. and Samson, I.M. (2006) The Aqueous Geochemistry of Gallium, Germanium, Indium and 322 Scandium. Ore Geology Reviews, 28, 57-102.

323 Yamaguchi, T., Niihara, M., Takamuku, T., Wakita, H. and Kanno, H. (1997) Scandium(III) hydration 324 in aqueous solution from X-ray diffraction and X-ray absorption fine structure measurements.

325 Chemical Physics Letters, 274, 485-490.

326 Yokosawa, T., Prestat, E., Polly, R., Bouby, M., Dardenne, K., Finck, N., Haigh, S.J., Denecke, M.A. 327 and Geckeis, H. (2019) Fate of Lu(III) Sorbed on 2-Line Ferrihydrite at pH 5.7 and Aged for 12 Years 328 at Room Temperature. II: Insights from STEM-EDXS and DFT Calculations. Environmental Science 329 and Pollution Research, 26, 5282-5293. 


\section{List of figures}

340 Figure 1 Representations of the supercells of Sc-substituted goethite $(2 \times 1 \times 3)(\mathbf{a})$ and hematite

$341(2 \times 2 \times 1)(\mathbf{b})$, and of the $\left[\mathrm{Sc}\left(\mathrm{H}_{2} \mathrm{O}\right)_{4}(\mathrm{OH})_{2}\right]^{+}$model complex (c) considered in the present study. The

342 two-tone sites can either be occupied by Fe (isolated model) or by Sc (paired model).

343 Figure 2 Comparison between experimental (red) and calculated (black) normalized Sc $K$-edge

344 XANES spectra for Sc-substituted goethite (a) and hematite (b) and Sc-adsorbed goethite and hematite

345 (c). Additional reference spectra of a $\mathrm{ScCl}_{3}$ solution (ca. $1 \mathrm{wt} \% \mathrm{Sc}$ ), Sc-adsorbed montmorillonite

346 (ca. $1 \mathrm{wt} \% \mathrm{Sc}$ ) and from a lateritic sample (ca. $750 \mathrm{ppm} \mathrm{Sc}$, Chassé et al. 2017) are given for

347 comparison in (c). Calculated spectra are shifted in energy to match the experimental A feature. The

348 symbols + indicate features discussed in the paper.

349 Figure 3 Experimental and calculated pre-edge regions of Sc $K$-edge XANES spectra of Sc-substituted

350 goethite: (a) isolated structural model; (b) paired structural model. The calculated electric dipole (E1)

351 and quadrupole (E2) contributions are displayed. The partial densities of the absorbing Sc (Sc*) $4 p$ and

$3523 d$ states, of the first six $\mathrm{O}$ neighbors $2 p$ states, of the first $\mathrm{Fe}$ and $\mathrm{Sc}$ neighbors $3 d$ states are shown.

353 The energy scale of the experimental spectra is shifted to match calculated spectra. The vertical line

354 indicates the Fermi level $\left(\mathrm{E}_{\mathrm{F}}\right)$. The ${ }^{*}$ symbol indicate features discussed in the paper. 
Feuille1

\begin{tabular}{|c|c|c|c|}
\hline & & & Goethite \\
\hline \multicolumn{3}{|c|}{ Interatomic distances $(\AA)$} & \\
\hline Oxygen neighbor & $\mathrm{Fe}-\mathrm{O}$ & $\mathrm{Sc}-\mathrm{O}$ (isolated) & Difference relative to $\mathrm{Fe}-\mathrm{O}$ distances $(\%)$ \\
\hline $\mathrm{O} 1$ & 1.90 & 2.03 & 6.84 \\
\hline $\mathrm{O} 2$ & 1.98 & 2.07 & 4.55 \\
\hline $\mathrm{O} 3$ & 1.98 & 2.07 & 4.55 \\
\hline $\mathrm{O} 4$ & 2.12 & 2.16 & 1.89 \\
\hline O5 & 2.12 & 2.16 & 1.89 \\
\hline O6 & 2.14 & 2.15 & 0.47 \\
\hline \multicolumn{4}{|r|}{ Hematite } \\
\hline \multicolumn{3}{|c|}{ Interatomic distances $(\AA)$} & \\
\hline Oxygen neighbor & $\mathrm{Fe}-\mathrm{O}$ & $\mathrm{Sc}-\mathrm{O}$ (isolated) & Difference relative to $\mathrm{Fe}-\mathrm{O}$ distances $(\%)$ \\
\hline $\mathrm{O} 1$ & 1.93 & 2.04 & 5.70 \\
\hline $\mathrm{O} 2$ & 1.93 & 2.04 & 5.70 \\
\hline O3 & 1.93 & 2.04 & 5.70 \\
\hline O4 & 2.14 & 2.17 & 1.40 \\
\hline O5 & 2.14 & 2.17 & 1.40 \\
\hline O6 & 2.14 & 2.17 & 1.40 \\
\hline
\end{tabular}

Table S1

Page 1 
Feuille1

\begin{tabular}{cc}
\hline Sc-O (paired) & Difference relative to Fe-O distances (\%) \\
\hline 2.03 & 6.40 \\
2.04 & 2.94 \\
2.08 & 4.81 \\
2.16 & 1.85 \\
2.16 & 1.85 \\
2.15 & 0.47 \\
\hline & \\
\hline & \\
\hline Sc-O (paired) & Difference relative to Fe-O distances (\%) \\
2.03 & 5.18 \\
2.03 & 5.18 \\
2.03 & 5.18 \\
2.19 & 2.34 \\
2.19 & 2.34 \\
2.19 & 2.34 \\
\hline
\end{tabular}

Page 2 
Feuille1

\begin{tabular}{ccc}
\hline \multicolumn{3}{c}{ Total energy (eV) } \\
\hline Goethite & Sc-substituted goethite (isolated) & Sc-substituted goethite (paired) \\
\hline 39459.87 & 40037.77 & 40615.77 \\
\hline Hematite & Sc-substituted hematite (isolated) & Sc-substituted hematite (paired) \\
\hline 67718.57 & 68296.14 & 68873.69 \\
\hline
\end{tabular}

Table S2 


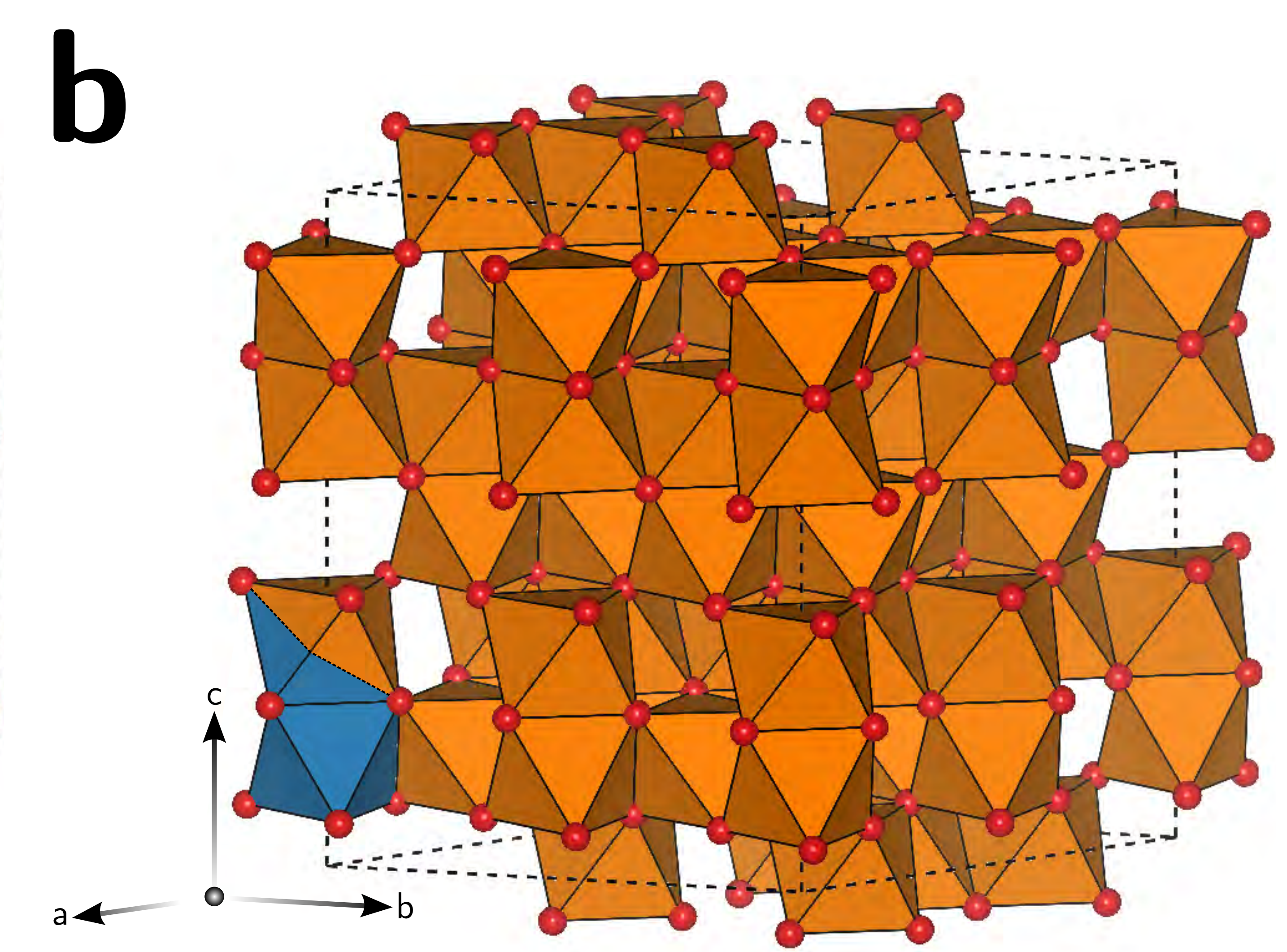

C

a

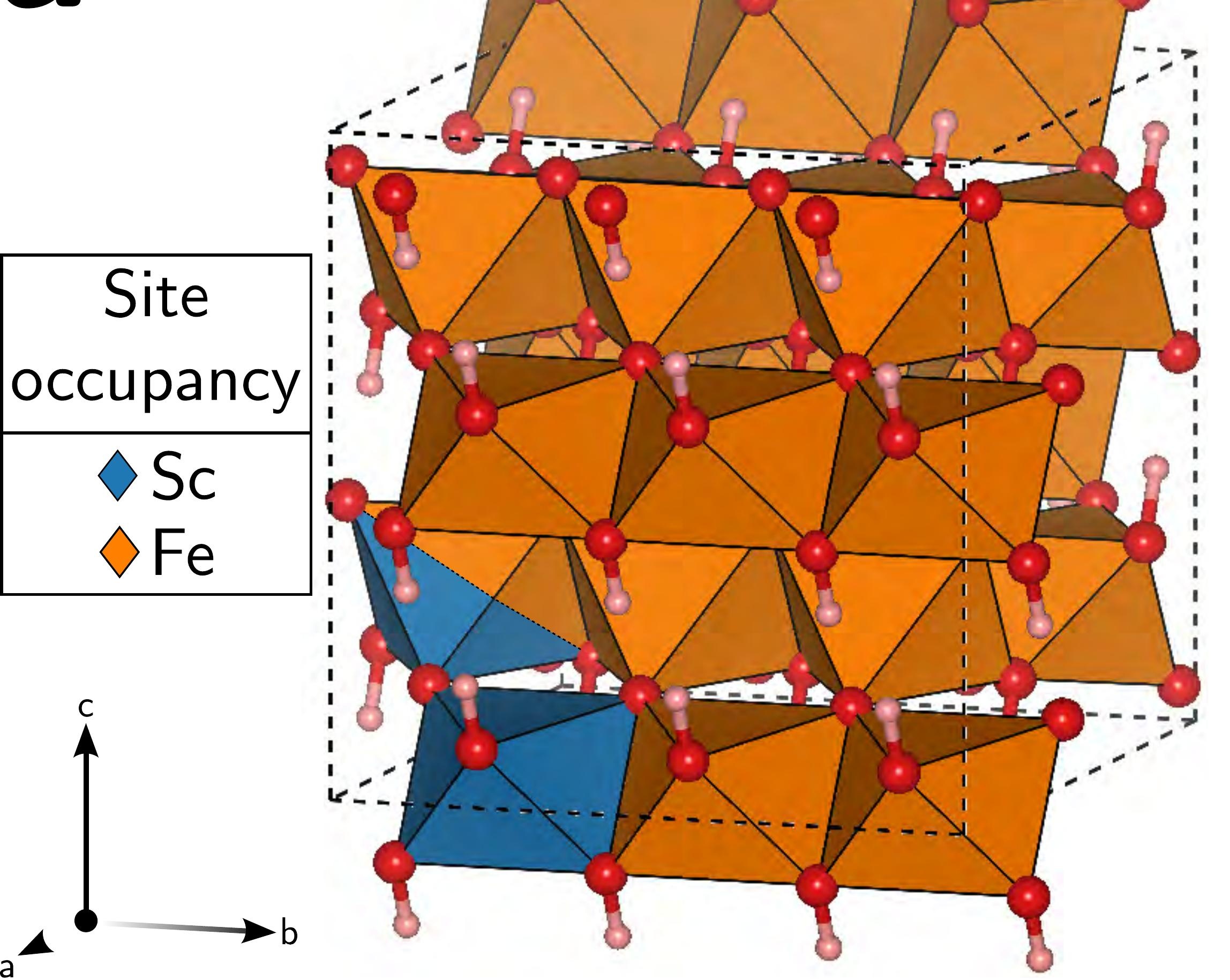

occupa

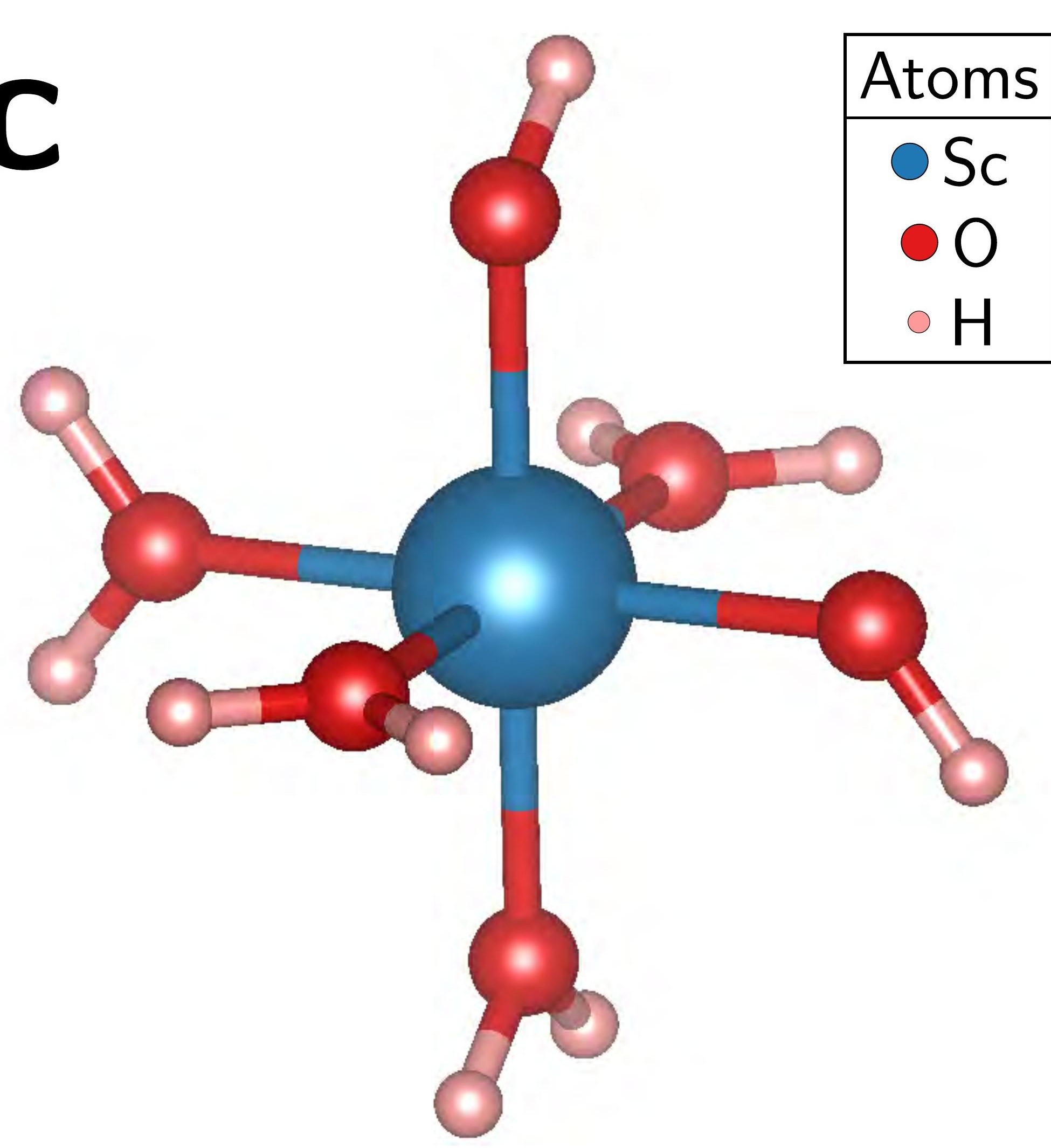

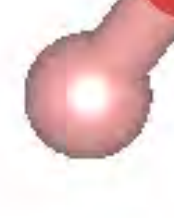
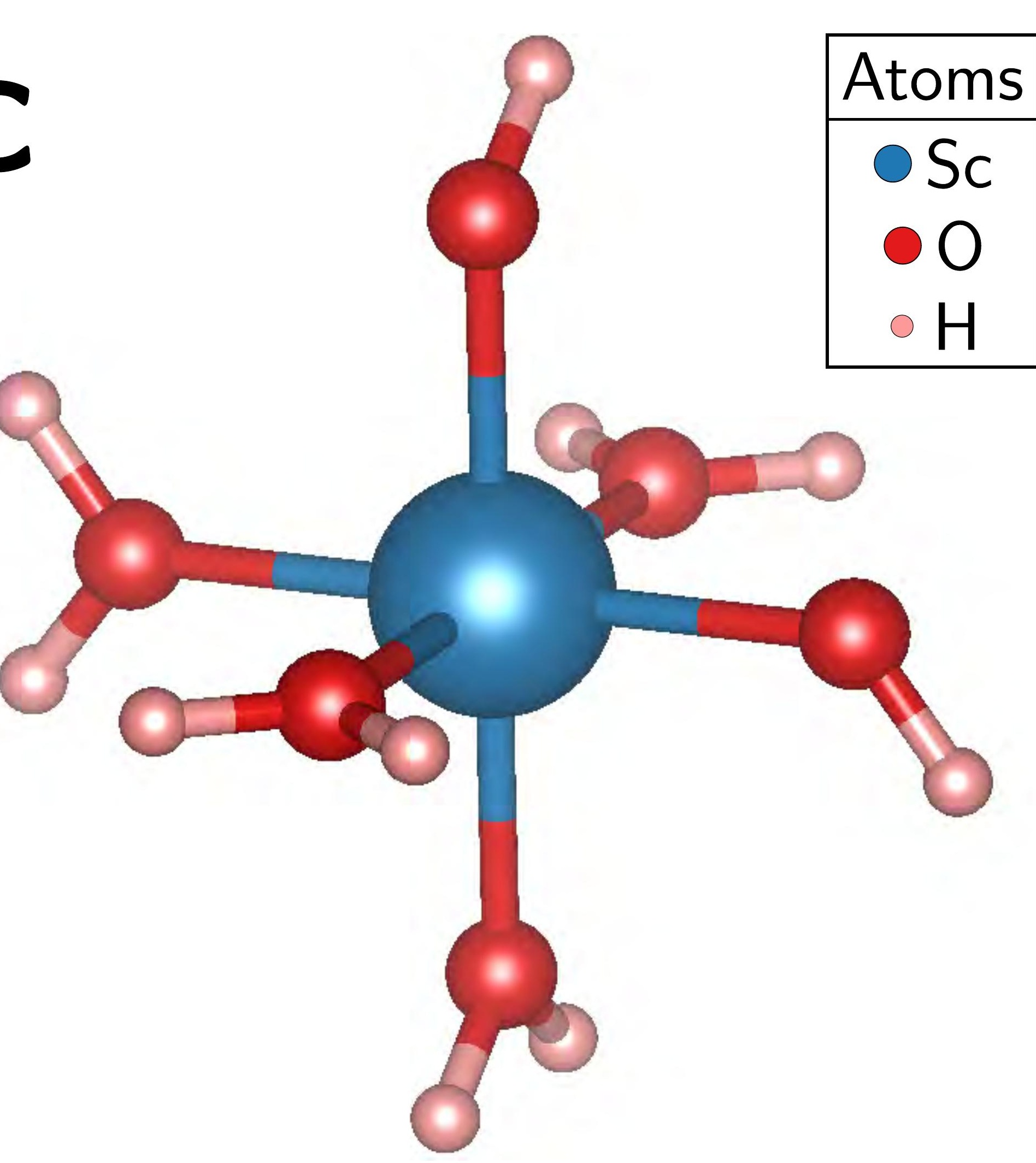
Figure 3

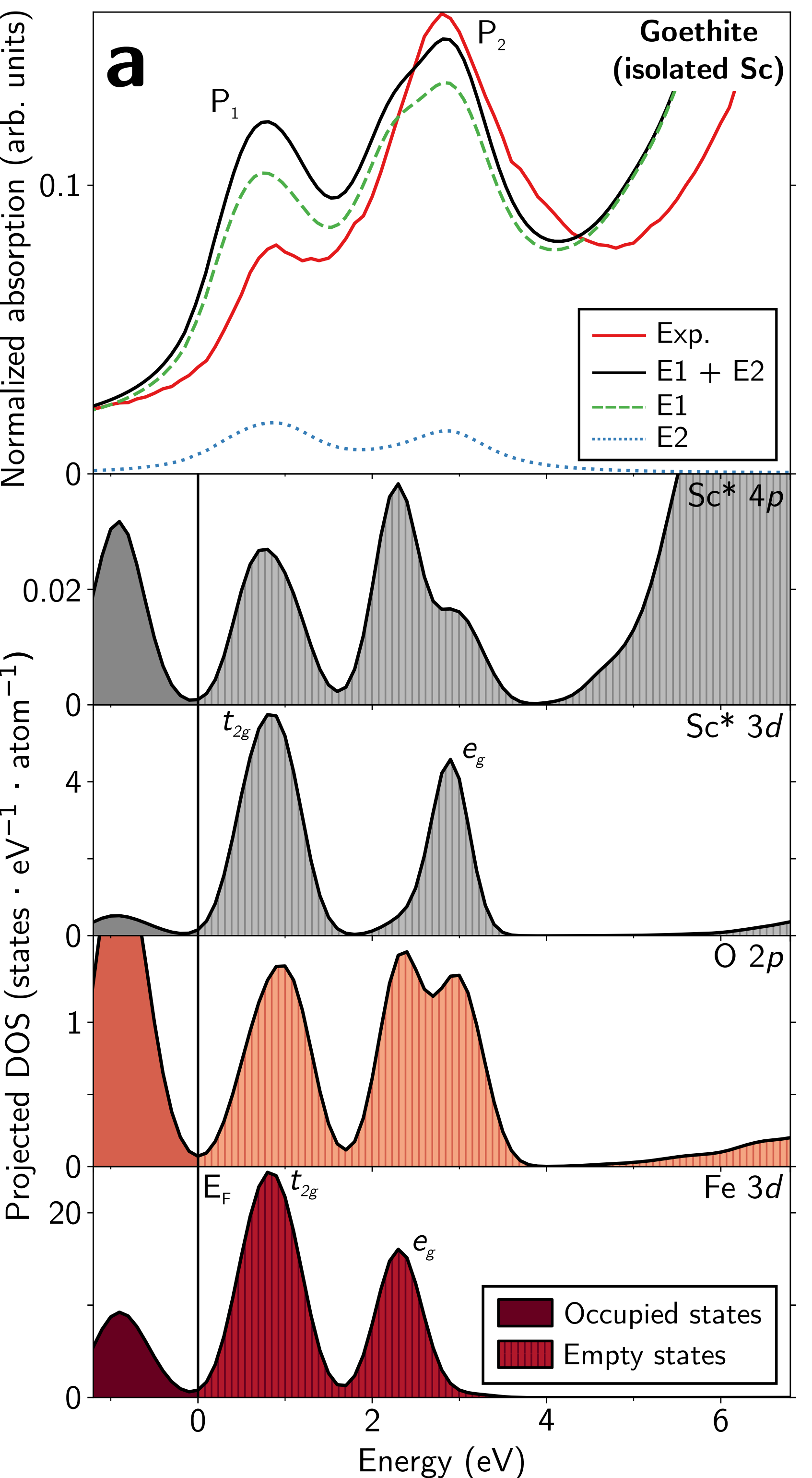

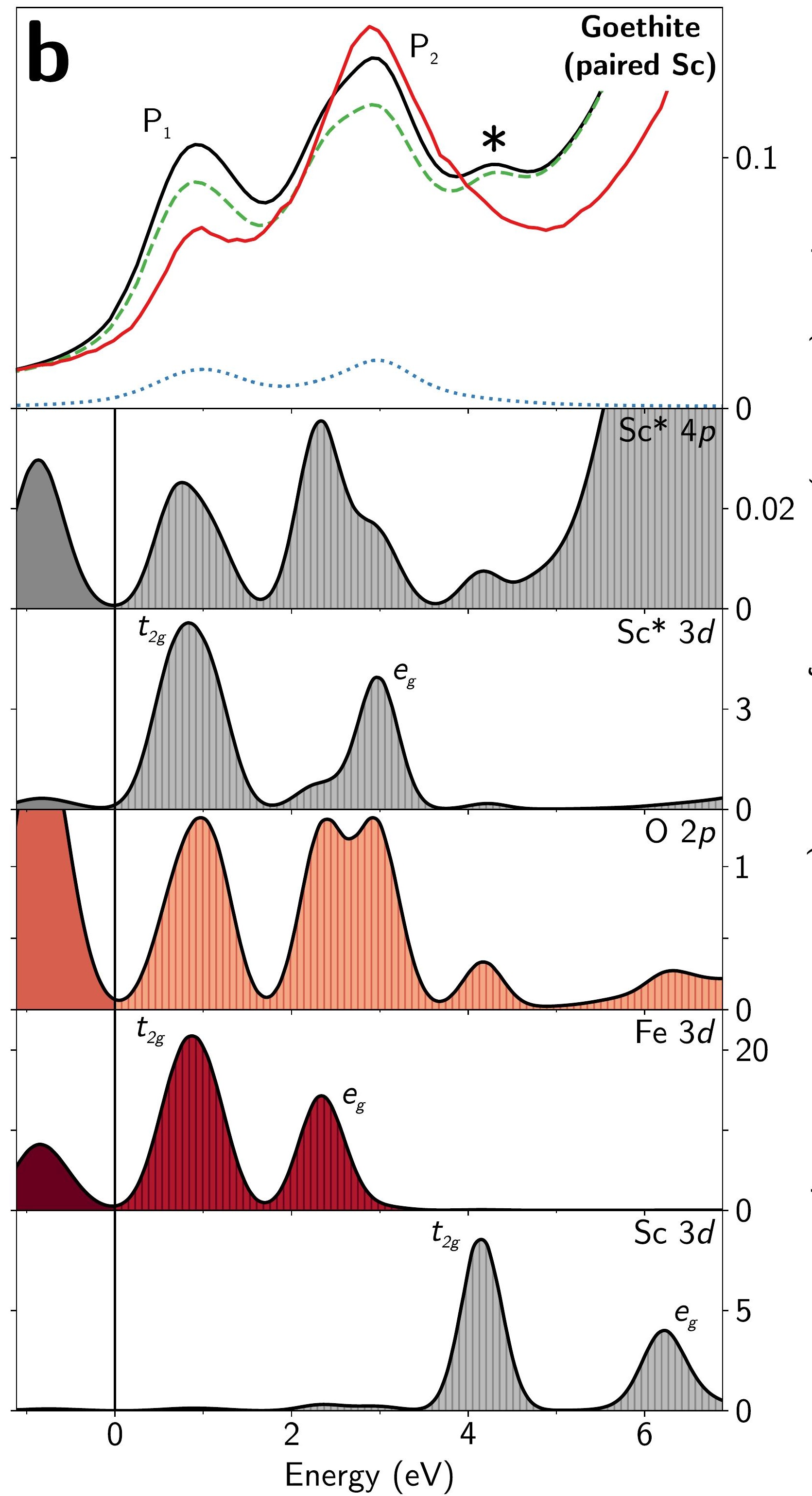

